\title{
Responsabilidade Social Corporativa: uma visão crítica a partir do estudo de caso da tragédia socioambiental da Samarco
}

\author{
JULIANA CAMPOS LOPES ${ }^{1}$ \\ JACQUES DEMAJOROVIC ${ }^{1}$ \\ ${ }^{1}$ Centro Universitário FEl, SÃo Paulo - SP, Brasil
}

\begin{abstract}
Resumo
Modelos de Responsabilidade Social Corporativa no setor de mineração tem usado de forma crescente os relatórios de sustentabilidade e as práticas ligadas ao modelo da Licença Social para Operar como forma de garantir a legitimidade de suas operações. O caso Samarco desafia o uso destas estratégias no país ao possibilitar que a empresa, considerada referência em práticas de responsabilidade social no setor de mineração, também se tornasse responsável por uma das maiores tragédias socioambientais do Brasil. Por meio do estudo de caso do rompimento da Barragem do Fundão, esta pesquisa buscou evidenciar as contradições do modelo Responsabilidade Social Corporativa da empresa que contribuíram para a emergência da tragédia. A coleta de dados incluiu os relatórios de sustentabilidade da empresa, documentos de órgãos públicos e entrevistas com stakeholders da companhia atingidos pela tragédia, sendo estes dados trabalhados a partir da análise de conteúdo. Os resultados indicam as contradições entre as informações disponibilizadas pela empresa e a percepção de riscos da comunidade. O modelo de responsabilidade social corporativa adotado pela Samarco priorizou o monitoramento da percepção da imagem e reputação da empresa junto a seus diferentes stakeholders, favorecendo a construção de laços de confiança com a população. No entanto, esta estratégia, aliada a dependência econômica do município, encobriu os riscos operacionais da barragem do Fundão resultando na ampliação da vulnerabilidade social da comunidade local.
\end{abstract}

Palavras-chave: Responsabilidade Social Corporativa. Relatórios de sustentabilidade. Licença social para operar. Reputação. Vulnerabilidade.

\section{Corporate Social Responsibility: a critical view from the case study of Samarco's socio environmental tragedy'}

\section{Abstract}

Corporate Social Responsibility models in the mining industry have often used sustainability reports and practices linked to the model of the Social License to Operate as a way to ensure the legitimacy of its operations. In Brazil, the Samarco case has challenged the implementation of both strategies, after the company, which was considered an example of social responsibility practices in the mining sector, was responsible for one of the worst social environmental tragedies in the country. This research adopts a case study of the Fundão dam collapse, to enhance the contradictions of the Corporate Social Responsibility model that contributed to the tragedy. Data collection included the company's sustainability reports, documents from public agencies, and interviews with the company's stakeholders affected by the tragedy. The data were worked through content analysis. The results show contradictions between the company's documents and the perception of the community about the risks. Corporate Social Responsibility adopted by Samarco prioritized monitoring the perception of image and the company's reputation with its different stakeholders, by reaching a high level of trust between the company and population. However, this strategy, combined with the economic dependence of the municipality, hid the operational risks of the Fundão dam resulting in increased vulnerability of the local community.

Keywords: Corporate Social Responsibility. Sustainability report. Social license to operate. Reputation. Vulnerability.

\section{Responsabilidad Social Corporativa: una visión crítica a partir del estudio de caso de la tragedia socioambiental de Samarco}

\section{Resumen}

Los modelos de responsabilidad social corporativa en la industria minera han utilizado cada vez más informes de sostenibilidad y prácticas vinculadas al modelo de la licencia social para operar como una forma de garantizar la legitimidad de sus operaciones. El caso Samarco desafía el uso de estas estrategias en el país al posibilitar que la empresa, considerada referencia en prácticas de responsabilidad social en el sector minero, también se hiciera responsable de una de las más grandes tragedias socioambientales de Brasil. Por medio del estudio de caso del rompimiento de la represa de Fundão, esta investigación buscó evidenciar las contradicciones del modelo responsabilidad social corporativa de la empresa que contribuyeron al trágico acontecimiento. La recolección de datos incluyó los informes de sostenibilidad de la empresa, documentos de organismos públicos y entrevistas con stakeholders de la compañía afectados por la tragedia, y estos datos se trabajaron a partir del análisis de contenido. Los resultados evidencian contradicciones entre los documentos generados por la empresa y la percepción de riesgos de la comunidad. El modelo de responsabilidad social corporativa de Samarco priorizó el monitoreo de la percepción de la imagen y reputación de la empresa ante sus stakeholders. Sin embargo, esta estrategia, combinada con la dependencia económica del municipio, ocultó los riesgos operacionales de la represa de Fundão, lo que resultó en el aumento de la vulnerabilidad de la comunidad local.

Palabras clave: Responsabilidad social corporativa. Informes de sostenibilidad. Licencia social para operar. Reputación. Vulnerabilidad. 


\section{INTRODUÇÃO}

O rompimento da barragem do Fundão, da Samarco, na região de Mariana, Minas Gerais, no Brasil, uma das maiores tragédias socioambientais causada por vazamento de resíduos de atividade de mineração da história, coloca o setor como um elemento fundamental da construção da sociedade de risco, conforme a obra clássica de Ulrick Beck (2011). Para o autor, a multiplicação das ameaças de natureza socioambiental fez com que a antiga sociedade industrial fosse substituída pela sociedade de risco. Enquanto a primeira é caracterizada pelos conflitos em relação à produção e distribuição de riqueza, a segunda estaria baseada no conflito relacionando produção e distribuição dos riscos. Beck (2011) argumenta que catástrofes ícones da década de 1980, destacando-se Bhopal (1984), Chernobyl (1986) e Exxon-Valdez (1989), não podem mais ser entendidas como fatalidades ou imprevistos, mas sim como algo inerente à modernidade que mostra, sobretudo, a incapacidade do conhecimento construído no século XX de controlar seus efeitos deletérios, como mostram os episódios mais recentes como o vazamento de óleo da British Petroleum no golfo do México (2010), a liberação de material radioativo em Fukushima (2011), no Japão, e o incêndio que atingiu o terminal de combustível da empresa Ultracargo, do Grupo Ipiranga, no porto de Santos (2015).

Frente a esse cenário, verifica-se um processo de maior articulação das partes interessadas de forma a ampliar a variedade dos atores no processo de governança corporativa. A solução de conflitos em torno de impactos ambientais e sociais, entendidos como responsabilidade do Estado e empresas, demanda uma gestão colaborativa, mediante acordos, consensos e participação pública (ANSELL e GASH, 2007) envolvendo também a sociedade civil (PRNO e SLOCOMBE, 2012). Assim, as empresas passaram a operar sob vigilância constante das forças sociais, e a mesma globalização que ampliou as oportunidades econômicas também tornou os negócios mais vulneráveis a ações articuladas de novos atores sociais que passaram a ter voz com o advento das tecnologias de comunicação. Nesse contexto, a responsabilidade social corporativa (RSC) apresenta uma nova visão em que se outorga papel político aos negócios para atuar em questões que extrapolam a simples geração de riqueza. A RSC é definida como as práticas empresariais que assegurem benefícios para a sociedade como um todo e não apenas para a própria empresa, superando muitas vezes aquilo que a legislação exige (MCWILLIAN e SIEGEL, 2001). No setor de mineração, duas estratégias têm sido valorizadas nos atuais modelos de RSC. A primeira trata da divulgação de informação, por meio de relatórios de sustentabilidade, entendidos como uma ferramenta de comunicação com os stakeholders colaborando para a reputação das organizações. Para Jenkins e Yakovleva (2006), há um crescimento significativo do uso de relatórios de sustentabilidade produzidos pelas empresas de mineração, embora também cresça a desconfiança entre as informações divulgadas e suas práticas empresariais. Um segundo aspecto é o uso do modelo da licença social para operar (LSO) nas práticas de RSC em diversos setores e, especificamente, na mineração (WILBURN e WILBURN, 2011). A proposta de uma LSO baseia-se na ideia de que a sociedade pode dar ou recusar o apoio a uma empresa e suas operações (PRNO, 2013; MOFFAT e ZHANG, 2014), sendo necessário que empresas de mineração avancem para além das obrigações formais (SANTIAGO e DEMAJOROVIC, 2016) a partir de práticas que valorizem o diálogo, a transparência e a confiança. Tais instrumentos, construídos no contexto de países desenvolvidos, vêm sendo adotados também nos países em desenvolvimento. Hilson (2012), no entanto, questiona a efetividade da replicação dos modelos de RSC nesses países. Argumenta que se trata de uma área cinza que demanda o avanço da pesquisa.

O caso Samarco representa um grande desafio para as práticas de RSC associadas a utilização destes instrumentos no país. Primeiro, por se tratar da maior tragédia socioambiental em nível mundial envolvendo o setor de mineração (FERNANDES, GOULART, RANIERI et al., 2016); segundo, pelo fato de a empresa ter ocupado uma posição de referência na área de mineração no que se refere as suas práticas operacionais e socioambientais. A companhia destacava-se no setor em relação a sua conduta referendada por diferentes prêmios bastante conhecidos no meio empresarial, como "Melhores e Maiores" (Revista Exame) e Troféu Transparência, em relação à divulgação de suas informações contábeis (O ESTADO DE S. PAULO, 2013). Além disso, a LSO figurava como um elemento importante da estratégia da Samarco. O relatório anual de sustentabilidade destaca que "por meio de uma conduta pautada no diálogo e transparência nas relações, a empresa conquistou a licença social para operar - ativo que ocupa lugar central em nosso Modelo de Sustentabilidade" (SAMARCO, 2014, p. 4). Nesse contexto, a questão de pesquisa que norteia este trabalho é que fatores explicam a fragilidade do modelo de RSC implantado na Samarco que contribuíram para a ocorrência da tragédia socioambiental. 0 objetivo deste trabalho é evidenciar as contradições do modelo de responsabilidade social adotado pela empresa Samarco a partir do estudo de caso do processo de rompimento da barragem do Fundão. 


\section{Impactos e conflitos na atividade de mineração}

A atividade de mineração é comumente associada a grandes impactos socioambientais por interferir de maneira significativa nos territórios em que se instala. Os impactos socioambientais da mineração não se limitam ao entorno das suas operações, expondo grupos variados de stakeholders a riscos gerados pelas suas atividades, sem a chance imediata de proteção legal ou compensação (ROCKSTRÖM, STEFFEN, NOONE et al., 2009). O estímulo ao processo migratório, conflito com outras atividades econômicas locais e grande consumo de recursos naturais são exemplos frequentes citados na literatura. As áreas rurais tendem a ser impactadas por poluição atmosférica, contaminação hídrica, desmatamento e erosão. Já nas regiões urbanas, os efeitos incluem inchaço urbano, favelização, aumento da violência, exploração sexual e sobredemanda dos serviços públicos de saúde, saneamento e segurança (DAVIS e TILTON, 2005).

A maior conscientização das comunidades em relação a esses impactos socioambientais também contribuiu para o aumento de conflitos entre a atividade de mineração e a população local que desafiam os processos de tomada de decisão de gestores do setor (MCMAHON e REMY, 2003). Em um trabalho com base em entrevistas com profissionais das áreas de finanças, jurídica e de sustentabilidade, além de estudos de caso empíricos, Franks, Davis, Bebbington et al. (2014) identificaram os conflitos mais comuns que surgem em áreas de mineração (Figura 1).

Figura 1

Conflitos em áreas de mineração

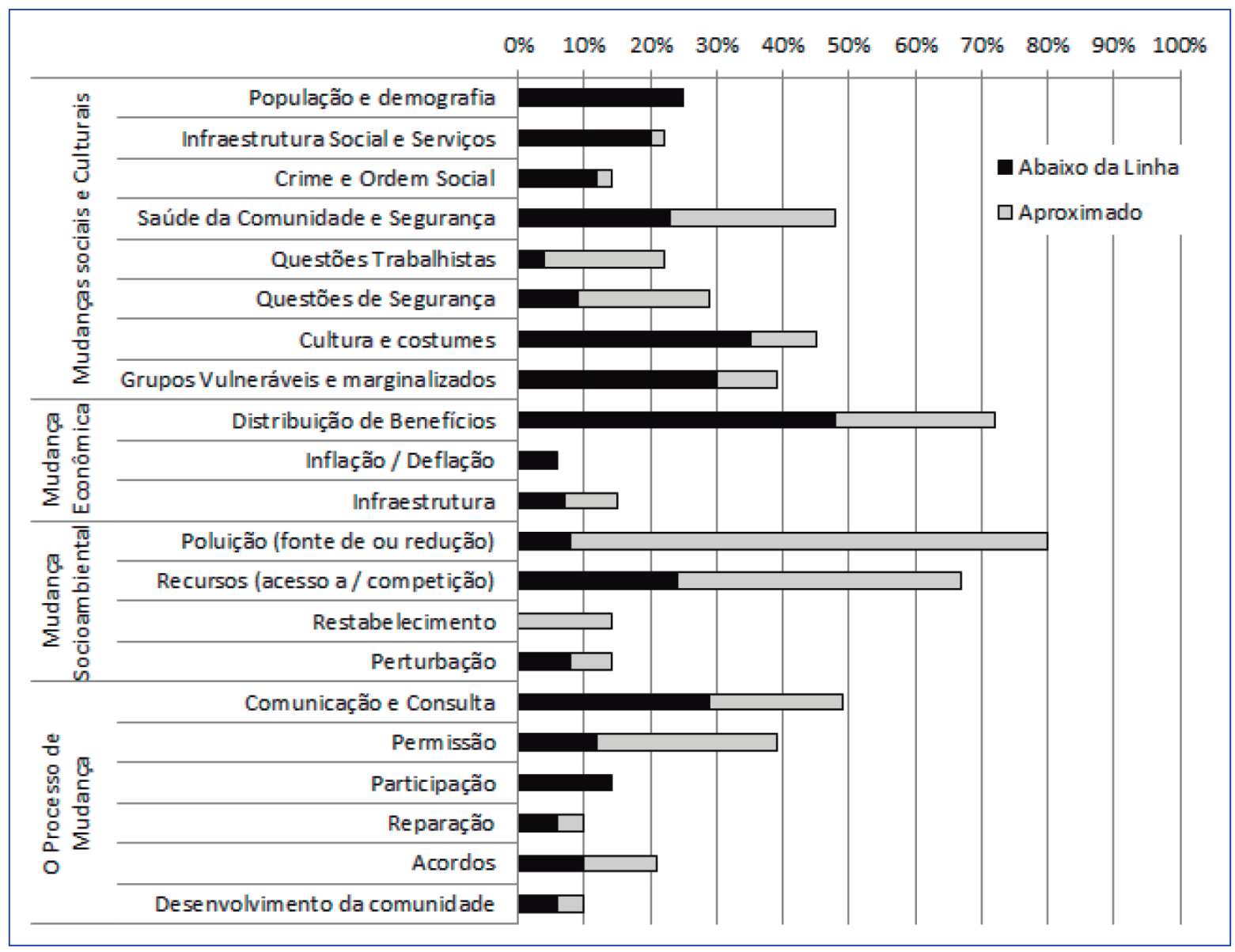

Fonte: Santiago (2016). 
A pesquisa destaca os conflitos associados à poluição, à distribuição de benefícios, à competição por recursos, às formas de comunicação e à consulta e problemas relacionados à saúde e segurança da comunidade. Os autores concluem que as companhias de mineração tendem a subestimar os impactos financeiros dos conflitos sociais. A título de exemplo, um projeto minerário de grande porte, com gasto de capital da ordem de US\$ 3 bilhões e US\$ 5 bilhões, acumulou perdas financeiras de US\$ 20 milhões por semana devido a atrasos na produção trazidos a valor presente, como resultado de um conflito. Os autores argumentam, portanto, que os conflitos sociais têm a capacidade de traduzir os riscos socioambientais para os custos do negócio e a tomada de decisão, consistindo em um importante direcionador de mudança do comportamento corporativo.

Sendo assim, a indústria tem procurado responder às demandas dos diferentes atores sociais a partir de abordagens que extrapolem as obrigações legais. Para Wilburn e Wilburn (2011), há um interesse crescente das empresas de mineração em adotar modelos de LSO em suas estratégias de RSC.

\section{A construção da licença social nas atividades de mineração}

A aprovação e ampla aceitação da sociedade para as empresas conduzirem suas atividades constroem a LSO, que não pode ser concedida pelas autoridades, pelas estruturas políticas ou pelo sistema legal (SOLOMON, KATZ e LOVEL, 2008).

Diferentes pesquisadores apontam que o termo LSO foi usado pela primeira vez por Jim Cooney, executivo da Placer Dome, em uma reunião promovida pelo Banco Mundial, em Washington, em 1997. Cooney defendeu que a "indústria teria que atuar de forma positiva para recuperar sua reputação e obter uma 'licença social para operar' por meio de um processo que, começando no âmbito das minas e de projetos individuais, criaria, ao longo do tempo, uma cultura e perfil públicos para a indústria mineradora" (THOMSON e BOUTILIER, 2011). Para Prno e Slocombe (2012), o conceito originou-se nos estudos sobre mineração realizados no norte do Canadá. Desde então, a LSO vem sendo amplamente utilizada por jornalistas, acadêmicos, empresas e analistas como a ideia de que os negócios cumprem com expectativas tácitas de reguladores, comunidades locais e o público em geral de forma a manter suas operações (GUNNINGHAM, KAGAN e THORTON, 2004)

Joyce e Thomson (2000) foram os primeiros a elaborar uma teoria a partir do conceito com base em sua experiência prestando consultoria para empresas que perderam a LSO. Com essa conceituação teórica conhecida como a teoria de dependência de recursos, os autores conferiram respeitabilidade à LSO ao incorporá-la à estratégia do negócio e à competitividade (BOUTILIER, BLACK e THOMSON, 2012).

Thomson e Boutilier (2011), por sua vez, sistematizaram um processo para ganhar e manter a licença social para operar. Segundo os autores, primeiramente, as empresas devem identificar todos os grupos que podem afetar ou são afetados pelo projeto. O método de referência, ou snowball, ajuda nesse sentido. Em segundo lugar, devem ser conduzidas entrevistas com os stakeholders para ouvir suas preocupações, obter as pontuações/ratings da LSO e desenvolver uma estratégia para: a) endereçar as preocupações dos stakeholders com as mudanças que a companhia planeja e pratica; b) construir acordo em torno de objetivos compartilhados para a comunidade/rede; e c) construir apoio para o papel da mineração na prosperidade da comunidade.

Thomson e Boutilier (2012) estabeleceram quatro níveis de obtenção da LSO: retenção, aceitação, aprovação e identificação psicológica; e três critérios de fronteiras que os separam, definidos essencialmente pela forma como a comunidade percebe a companhia em três limites: legitimidade, credibilidade e confiança, esquematizados na Figura 2. 
Figura 2

A pirâmide modelo da LSO

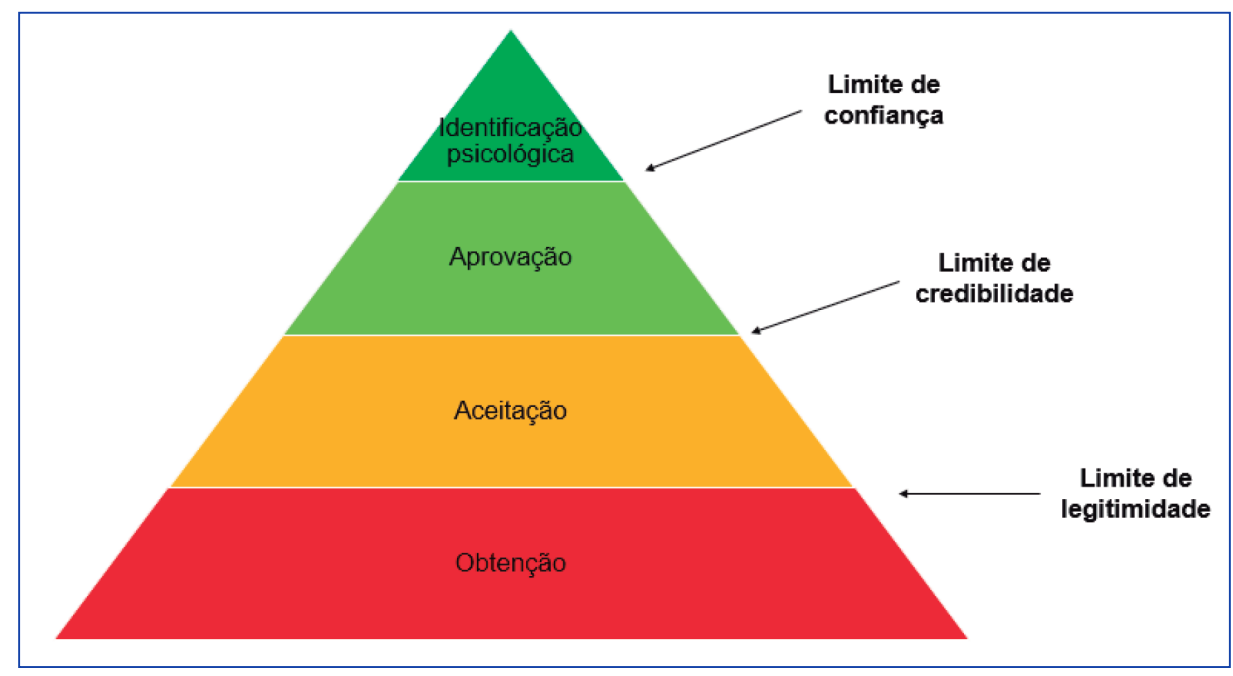

Fonte: Thomson e Boutilier (2011).

Os autores definem os componentes essenciais para cada uma das fronteiras, começando pela legitimidade que consiste na "aceitação do público em geral e das organizações relevantes de elite do direito de uma organização a existir e exercer suas atividades de maneira eleita" (THOMSON e BOUTILIER, 2011, p. 14). Na fase seguinte, para conquista de credibilidade, a transparência se mostra fundamental e "resulta da abertura de informação e tomada de decisão que demonstra como a companhia é consistente na maneira em que trata os distintos grupos" (THOMSON e BOUTILIER, 2011, p. 15). Para ganhar credibilidade, portanto, as companhias devem cumprir promessas de curto prazo por meio de processos participativos para identificar as prioridades da comunidade que a companhia pode ajudar a realizar. Os autores também recomendam a verificação das declarações da companhia por uma terceira parte, bem como capacitar a comunidade para que ela desempenhe um papel regulador das atividades da empresa por meio de comitês, por exemplo.

Segundo os autores, quando a empresa conquista a legitimidade e a credibilidade, é provável que a comunidade outorgue a licença social, que representa a ausência de risco sociopolítico e que a comunidade já não pode mais ser influenciada pela "retórica nós-contra-eles de movimentos antimineração" (THOMSON e BOUTILIER, 2011, p. 18).

Em um estágio mais avançado de confiança, a comunidade - de boa vontade - se torna vulnerável às ações da companhia, pois o nível de confiança é tal que ela passa a crer que a companhia atua sempre pelos interesses da comunidade. Os autores defendem que, quando a comunidade percebe a empresa como totalmente confiável, existe um sentimento de copropriedade e a empresa se transforma em um membro da rede social da comunidade (THOMSON e BOUTILIER, 2011). No entanto, é importante lembrar que nenhum desses estágios é permanente, e mesmo em uma situação de identificação psicológica pode ocorrer a perda da licença social. Portanto, a LSO deve ser pensada como um processo de contínua negociação em vez da lógica convencional de um contrato legal com cláusulas e ações bem definidas entre as partes envolvidas (FRANKS e COHEN, 2012).

Além do desenvolvimento de modelos para LSO, pesquisas têm avançado também para crítica da efetividade desse modelo. Segundo McMahom e Remy (2003), em uma situação ideal, a comunidade do entorno do projeto, o governo central e a empresa de mineração mantêm um diálogo permanente para facilitar o desenho e a implementação de um plano de desenvolvimento local e regional. No entanto, com base em estudos sobre a relação de empresas de mineração com as comunidades no Chile, Peru e Equador, os pesquisadores observaram que, normalmente, as empresas negociam com o governo central e com a comunidade separadamente. Essa prática, chamada pelos autores de "triângulo dos lados", é comum nos países latino-americanos, em que o governo central tem um papel fundamental no estabelecimento prévio do regime legal e fiscal, das regulações ambientais e dos principais projetos de infraestrutura, para logo depois outorgar a licença para exploração da mina. 
Schneider e Scherer (2015), por sua vez, destacam que, nessas circunstâncias, cada vez mais stakeholders são individualmente expostos aos riscos e custos resultantes dos negócios das empresas em casos em que o poder regulatório é incapaz de mitigar ou socializar esses riscos.

De forma a lidar com esta fragilidade, estudiosos têm feito recomendações para a obtenção e manutenção da LSO que incluem a necessidade de comunicação antes e após a implementação do projeto, transparência na divulgação de informações, desenvolvimento de mecanismos de resolução de conflitos e processos culturalmente adequados de tomada de decisão (PRNO, 2013).

Joyce e Thomson (2000) apontaram como fatores-chaves da LSO: a) consultar a comunidade de forma extensiva e assegurar que esteja bem informada não somente sobre a avaliação de impacto socioambiental, mas também durante o processo de permissão; e b) considerar um modelo de engajamento construtivo, em que múltiplas partes trabalham juntas para alcançar objetivos comuns.

Uma pesquisa conduzida em janeiro de 2005 com os participantes da Conferência BC and Yukon Chamber of Mines Cordilleran Round-Up apontou as três respostas mais frequentes sobre como obter uma LSO: a) manter uma reputação corporativa positiva; b) entender cultura, linguagem e história dos grupos; e c) assegurar uma comunicação aberta entre todos os stakeholders (NELSEN e SCOBLE, 2006).

A partir de estudos de caso comparativos de quatro minas nos Estados Unidos, Papua-Nova Guiné, Canadá e Peru, Prno (2013) identificou cinco fatores-chave relacionados à manutenção da LSO: a) o contexto é chave, não havendo espaço para generalizações, uma vez que cada mina é única pelas suas características sociais, ambientais, culturais e econômicas; b) a licença social é construída com base em relacionamentos; c) a sustentabilidade é uma preocupação dominante para as comunidades; d) a geração de benefícios em âmbito local e a participação pública têm um papel crucial; e) adaptabilidade é necessária para lidar com a complexidade. Segundo o autor, esses fatores juntos podem servir como "princípios norteadores" para a manutenção da LSO pela indústria de mineração.

Moffat e Zhang (2014) apontam a confiança como elemento central em um modelo de LSO, representando o mecanismo pelo qual a percepção dos impactos das operações minerárias se mescla às experiências e percepções de justiça dos processos relacionados à aceitação e à aprovação da operação de uma mina. Zhang, Moffat, Lacey et al. (2015) apontam três elementos principais que afetam a confiança pública no setor de mineração e, portanto, a aceitação das suas atividades em escala nacional: a) distribuição justa dos benefícios da mineração; b) procedimentos justos nas interações entre o setor de mineração e a sociedade; c) confiança nos acordos de governança em torno da atividade minerária. Concluem que, para alcançar uma prática de mineração mais sustentável, em que o conflito social seja minimizado e os benefícios ampliados, tanto as empresas de mineração como os governos precisam revisar seus métodos de engajamento dos cidadãos para construir confiança em suas relações.

\section{METODOLOGIA}

Por se tratar de fenômeno recente na literatura, optou-se por uma abordagem qualitativa de caráter exploratório e interpretativo, e a estratégia de pesquisa foi a de realização de um estudo de caso. Uma das fases importantes da aplicação dessa técnica é a seleção apropriada do estudo de caso. Para Eisenhardt (1989), a singularidade do caso permite construir hipóteses sobre temas pouco pesquisados.

A dimensão da tragédia da Samarco não tem precedentes no cenário mundial. O mar de lama percorreu 663 km, da barragem do Fundão, localizada próxima à cidade de Mariana, até a Foz do Rio Doce, sendo o custo da recuperação dos ecossistemas impactados avaliados em US\$ 20 bilhões (FERNANDES, GOULART, RANIERI et al., 2016). Para fins de pesquisa, delimitou-se a unidade de análise ao Alto Rio Doce, região onde se deflagrou o rompimento da barragem e também a mais rural entre os municípios atingidos.

As técnicas de coleta de dados incluíram a análise documental e a realização de entrevistas. Tal análise foi dividida em duas fases. Na primeira, o foco centrou-se nos documentos públicos disponíveis, incluindo relatórios gerados por organizações públicas e não governamentais (ONGs), buscando o histórico do processo de licenciamento, construção e operação da barragem 
do Fundão. Complementou-se a análise documental com a leitura dos relatórios de sustentabilidade, de 2005 a 2014, com o objetivo de identificar também nesse material elementos que se relacionassem com algumas das principais categorias discutidas na revisão da literatura associadas à construção da LSO, como transparência e diálogo. A segunda fonte de coleta de dados consistiu na realização de entrevistas semiestruturadas com múltiplos stakeholders. Dezessete entrevistas foram realizadas, incluindo moradores (12), representante da prefeitura (1), representante do Ministério Público (1), representante da Arquidiocese (1), representante da Samarco (1) e representante da sociedade civil organizada (1). As entrevistas, assim como a visita de campo, concentraram-se no distrito de Bento Rodrigues, em Mariana, e também o município de Barra Longa. As entrevistas incluíram questões relacionadas ao investimento nas comunidades, canais de comunicação, diálogo e transparência, riscos e gestão de impactos socioambientais, e ações da empresa após a tragédia.

Optou-se pela análise de conteúdo como estratégia, que se mostrou adequada para o estudo em questão, pois permite a decomposição do discurso e a identificação de unidades de análise ou grupos de representações para uma categorização dos fenômenos, quando então se torna possível uma reconstrução de significados que apresentem uma compreensão mais aprofundada da interpretação de realidade do grupo estudado (SILVA, GOBBI e SIMÃO, 2011). Para tanto, utilizou-se uma análise de conteúdo por categorização, buscando estabelecer relações de equivalência com os elementos considerados essenciais nos modelos de LSO necessários para assegurar a legitimidade de projetos minerários. As categorias analíticas foram baseadas no levantamento da literatura conforme apresentado no Quadro 1 a seguir.

\section{Quadro 1}

Levantamento na literatura

\begin{tabular}{|l|l|}
\hline \multicolumn{1}{|c|}{ Categorias } & \multicolumn{1}{c|}{ Referência } \\
\hline Confiança & Moffat e Zhang (2013); Thomson e Boutilier (2011) \\
\hline Diálogo e consulta & Joyce e Thomson (2000); McMahon e Remy (2003) \\
\hline Transparência & Prno (2013) \\
\hline Aceitação & Thomson e Boutilier (2011) \\
\hline Risco & Schneider e Scherer (2013) \\
\hline Divulgação de informações & Prno (2013) \\
\hline Reputação & Nelsen e Scoble (2006) \\
\hline
\end{tabular}

Fonte: Elaborado pelos autores.

\section{RESULTADOS}

\section{Conjuntura econômica e política da tragédia}

De acordo com Milanez, Santos, Wanderley et al. (2015), no período entre 2003 e 2013, as importações globais de minérios saltaram de US\$ 38 bilhões para US\$ 277 bilhões (um aumento de 630\%). O Brasil foi um dos países mais beneficiados nesse período, ocupando o segundo lugar em exportações globais de minérios, sendo responsável por 14,3\% das exportações desse bem em todo o mundo. Ao longo desses anos, aprofundou-se a dependência econômica do Brasil em relação ao setor mineroexportador. No mesmo período, a participação dos minérios na exportação do país passou de $5 \%$ para $14,5 \%$, tendo o minério de ferro correspondido a $92,6 \%$ desse total. A Samarco pode ser identificada como um ícone desse modelo, que se consolidou na década de 1970, consistindo em um complexo mina-mineroduto-pelotizadora-porto que tinha como principal função abastecer o mercado global com bens naturais semitransformados extraídos no Brasil.

Entretanto, o mercado de minério em geral, e do minério de ferro em particular, é caracterizado por um caráter cíclico. Saindo de um patamar de US\$32 (jan./2003), o preço da tonelada de minério de ferro chegou a um pico de US\$196 (abr./2008) e, a partir de 2011, iniciou uma tendência de queda, chegando a US\$ 53 (out./2015) (BANCO MUNDIAL, 2015). 
Figura 3

Preço do minério de ferro no mercado internacional

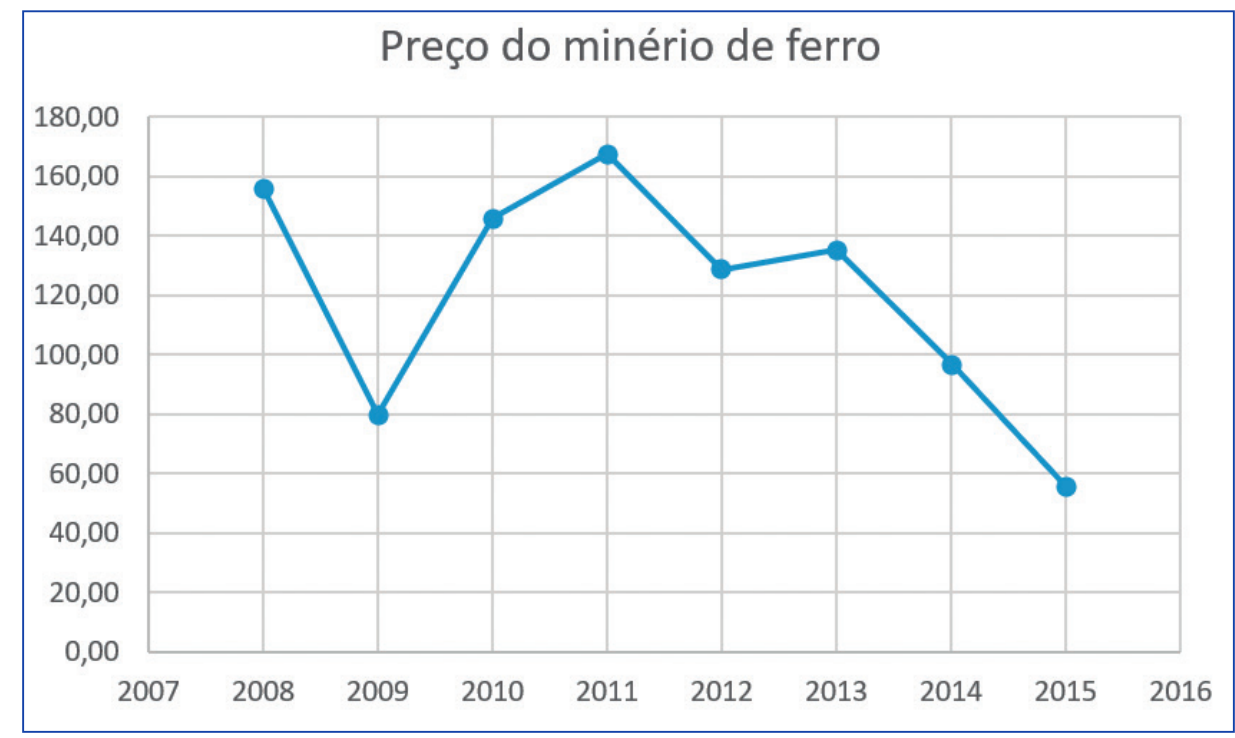

Fonte: Lopes (2017).

Para Milanez, Santos, Wanderley et al. (2015), entender essa dinâmica é importante para compreender o caráter estrutural do rompimento da barragem do Fundão. Davies e Martin (2009) argumentam que há um aumento da ocorrência dos rompimentos de barragens de rejeitos durante o processo recessivo dos ciclos de preços dos minérios. Segundo os autores, as causas para esse comportamento são várias. Pode-se destacar a pressa para obter o licenciamento no período de preços elevados, levando ao uso de tecnologias inapropriadas e à escolha de locais não adequados para a instalação dos projetos; pressão sobre as agências ambientais pela celeridade no licenciamento, resultando em avaliações incompletas dos riscos e impactos dos projetos; e intensificação da produção ou pressão por redução nos custos a partir do momento em que os preços voltam aos patamares usuais.

No caso específico da Samarco, todos esses elementos podem ser observados, reforçando a tese de Davies e Martin (2009). A instalação da empresa na região de Mariana se deu na década de 1970, coincidindo com a retomada da atividade de mineração em Minas Gerais com o novo ciclo de exploração do minério de ferro. A década de 1970 foi marcada pela implementação de grandes projetos de mineração e investimentos estrangeiros, tendo em vista que o novo Código Mineral de 1967 permitiu a participação de capital estrangeiro em projetos de exploração de mineração. A instalação da Samarco coincide com o período em que a mineração foi reintroduzida na região de Mariana após um período de decadência econômica desde o fim do primeiro ciclo de mineração de ouro. A perspectiva de geração de emprego e renda fez com a empresa conquistasse a aprovação das autoridades e da população local. Milanez, Santos, Wanderley et al. (2015) defendem que essa característica, somada às ações de "merchandising" e investimento socioinstitucional da companhia, estimulou uma conivivência das autoridades locais, regionais e da comunidade em geral com eventuais impactos negativos gerados pela empresa no território.

No caso da barragem do Fundão, problemas foram identificados já na fase de escolha da localização da barragem. O estudo de impacto ambiental apresentava duas alternativas que implicariam menores riscos para comunidades próximas, como Bento Rodrigues. Milanez, Santos, Wanderley et al. (2015) mostram que a decisão da instalação da barragem do Fundão considerou apenas a variável econômica. Além disso, posteriormente à tragédia, um relatório elaborado por um painel de especialistas independentes, contratado pelos acionistas Vale e BHP Billiton, empresas controladoras da Samarco, apontaram incidentes envolvendo a barragem desde 2009 (LOPES, 2017). A análise de documentos da investigação da Força-Tarefa Rio Doce 263, realizada pelo Ministério Público Federal da Procuradoria da República nos Estados de Minas Gerais e Espírito Santo, revelou que os riscos do sistema de barragens do complexo do Fundão foram objeto da reunião do conselho da administração em 10 de agosto de 2011. Na ocasião, foram apresentadas as conclusões de um relatório do Independent Tailing Review Board (ITRB), que identificou a insuficiência da drenagem interna do Fundão, resultando em saturação do talude de jusante do 
Fundão com risco de sua ruptura. O ITRB consistia em um órgão externo, independente, formado por especialistas nacionais e internacionais, e de controle dentro da gestão da Samarco.

Além disso, o ITRB também chamou a atenção para a necessidade de a Samarco prestar maior atenção nas comunidades de jusante com relação às ações emergenciais. Diante do exposto pelo ITRB, o conselho administrativo da Samarco assim se manifestou na reunião: "O Conselho tomou conhecimento das informações e reforçou que, depois da segurança, a redução de custos deveria ser o foco principal da gestão" (BRASIL, 2016, p. 52).

No entanto, segundo apurou o Ministério Público Federal (MPF), a Samarco contratou a empresa VOGBR Recursos Hídricos \& Geotecnia LTDA para elaborar o laudo de condições de estabilidade da barragem do Fundão. Em 2015, a VOGBR emitiu a declaração de estabilidade da barragem, omitindo dados relevantes, como a leitura piezométrica dos instrumentos instalados, precisamente no recuo do eixo da barragem. A referida empresa, mesmo conhecendo os vários problemas apresentados na barragem e todas as situações de risco decorrentes, declarou a segurança da estrutura, tendo pleno conhecimento de suas responsabilidades como pessoa jurídica responsável pelo referido laudo, incidindo no crime previsto no art. 69-A, § 2으, da Lei no 9.605/95, segundo concluiu a investigação do MPF (BRASIL, 2016, p. 264).

Para o Ministério Público (MP) de Minas Gerais, a Samarco levou os órgãos ambientais a erro por ter omitido informações sobre a disposição de minérios da Vale no Fundão. A mineradora também teria omitido condicionantes de funcionamento ao pedir a revalidação da licença de operação da barragem. A promotoria apresentou denúncia de que a Samarco fraudou documentos ao pedir licenciamento para a barragem. Segundo o MP, a barragem do Fundão não tinha licença ambiental para receber rejeitos da Vale, controladora da Samarco junto com a BHP Billiton. Segundo apurou a Polícia Federal (PF), 28\% dos rejeitos lançados no Fundão em 2014 correspondiam à Vale. O MP ainda denunciou que as obras feitas no local em que a barragem se rompeu não tinham autorização do órgão competente, a Fundação Estadual do Meio Ambiente (FEAM) (COISSI e BRAGA, 2016).

\section{As contradições nos relatórios de sustentabilidade e entrevistas}

Considerando os documentos analisados referentes ao histórico do rompimento da barragem, a primeira categoria analisada foi a de riscos, especialmente no que se refere à barragem. As referências passaram de 20 menções em 2006 para 44 em 2014, ocupando a 44a posição entre as palavras mais frequentes da edição de 2014. Ao mesmo tempo, os relatórios privilegiam as informações que indicariam a segurança dos processos de forma a mitigar problemas em função de acidentes. A empresa informa no relatório de sustentabilidade de 2014 a realização de um simulado para verificar ações, comportamentos, procedimentos e recursos em situações de emergência. Cita estudos visando o reaproveitamento de materiais descartados e a filtragem de rejeitos, uma área de investimento dentro do pilar de ecoeficiência e inovação do seu programa de desenvolvimento socioinstitucional. Observa-se esse fato como um indício de que a geração de resíduos e a dependência do modelo de barragens era uma preocupação.

Sob a ótica da segurança de nossas operações, dispomos do Plano de Ações Emergenciais (PAE) das barragens, que aborda o funcionamento das estruturas de disposição de rejeito e possíveis anomalias ou situações de emergência. Com base nesse documento, que atende aos requisitos legais sobre gestão de barragens, aplicamos, em 2013, 1.356 horas de treinamentos com os empregados envolvidos direta ou indiretamente nas atividades (SAMARCO, 2013, p. 75).

Esses esforços, no entanto, não eram objeto de diálogo com as comunidades do entorno, como se vê mais adiante na análise das entrevistas. Tampouco há indícios de que os procedimentos citados no contexto do PAE das barragens tenham sido efetivamente implementados diante do rompimento da barragem do Fundão, inclusive em desagravo ao marco regulatório de barragens que prevê a instalação de sistema de alerta e a disponibilização de equipes treinadas para assessorar as comunidades em casos de emergência. Interessante notar que a palavra segurança ocupa cada vez menos espaço no relatório. Se em 2005 a palavra aparece 104 vezes, em 2014 ela é mencionada apenas 39 vezes. Interessante notar também que a perda de importância da palavra segurança ocorre paralelamente a um período em que se ampliam os riscos de acidentes no trabalho. De 2008 a 2014, verificou-se nos relatórios que dobrou a taxa de acidentes, pulando de 0,61 para 1,27. Importante destacar que desde 2011 a Samarco vinha trabalhando com preços cada mais reduzidos do minério de ferro no mercado internacional.

Buscou-se ainda menções diretas a Bento Rodrigues, uma vez que era a comunidade mais próxima da barragem, e, conforme demonstrado na análise documental, a mais vulnerável em caso de rompimento. Percebe-se que a presença de Bento Rodrigues, 
que já era pouco expressiva, desaparece dos relatórios a partir de 2009, não havendo mais nenhuma menção direta ao distrito nas publicações a partir desse ano. As poucas citações encontradas entre 2005 e 2008 dizem respeito a investimentos pontuais, como contribuições para a reforma da igreja do município e investimentos na associação de moradores e produtores locais.

Programa que visa à melhoria da qualidade de vida da comunidade de Bento Rodrigues, em Mariana (MG), a partir de ações de educação ambiental, formação de lideranças e fortalecimento da agroindústria. Em 2005 foi construída uma estação de tratamento de água no município. Além disso, foram oferecidos tratamentos oftalmológicos e doados óculos para a comunidade. Investimento: R\$ 7,2 mil (SAMARCO, 2005, p. 129).

Se a questão dos riscos operacionais pouco dialogava com a realidade apontada no histórico apresentado do rompimento, encontra-se nos relatórios uma evolução da questão reputacional. Os indícios nesse sentido podem ser observados à medida que a questão de reputação cresce em importância no relato da companhia. Enquanto, em 2005, não havia nenhuma menção à reputação, em 2014 essas citações chegam a 30. No relatório de 2011, a empresa faz menção à "Plataforma de Reputação da Samarco", desdobramento da pesquisa realizada junto a suas partes interessadas aplicando a Metodologia RepTrak ${ }^{\mathrm{TM}}$ Deep Dive, do Reputation Institute, cujo resultado indicou que a Samarco possuía reputação "forte" junto aos seus públicos de relacionamento. Segundo a empresa, esse estudo tinha como objetivo apontar "as oportunidades para impactar positivamente a reputação e os riscos que devem ser gerenciados" (SAMARCO, 2011, p. 31).

De maneira geral, as citações a processos de consulta, diálogo e transparência não são predominantes. Na publicação de 2005, não há qualquer evidência de práticas de consulta a partes interessadas, e a palavra "diálogo" aparece apenas 11 vezes, sequer figurando entre as mil palavras mais frequentes no relatório.

Em 2014, o quadro é distinto, com 4 menções à consulta a partes interessadas e 22 a diálogo, porém sem mais informações sobre as atividades específicas realizadas com cada comunidade, não sendo possível identificar as que aconteciam em Bento Rodrigues. Ainda assim, o conteúdo dos relatórios reforça a transparência da Samarco com relações aos impactos positivos e negativos para a comunidade.

Entre os fóruns de diálogo estruturados estão os encontros com a comunidade; o Fórum de Acompanhamento das Licenças Ambientais da Samarco (Falas, implantado no Espírito Santo); os Comitês de Desenvolvimento Local; os encontros de Liderança; e o Programa de Visitas. Nesses fóruns, tratamos dos impactos negativos e positivos, qualificamos e desenvolvemos as comunidades, levamos informações sobre a Empresa e ouvimos as pessoas (SAMARCO, 2014, p. 42).

Ao passar à análise das entrevistas, encontramos contradições especialmente no que se refere às informações que chegavam aos moradores. Os relatos dos moradores de Bento Rodrigues afetados pela ruptura da barragem mostram que a segurança do complexo de barragens sempre foi uma preocupação deles, devido à proximidade de sua localização do povoado. Segundo relato dos moradores, confirmado em entrevista com o porta-voz da empresa, o tema era discutido frequentemente com os funcionários da Samarco em suas visitas à comunidade.

Foi uma senhora lá no meu restaurante em 2010 dizendo que estava ouvindo falar que tinha uma barragem que estava para estourar [...]. Então essa barragem deu um problema, mas eles conseguiram contornar. Já tinha dado um alarme, mas eles não comunicaram a gente. Eles falaram que não era para comunicar nada porque eles tinham o controle da situação. Eles já sabiam que ela já estava com problema (Moradora de Bento Rodrigues).

Apesar da percepção das condições inseguras da barragem por parte da população, é importante destacar que os moradores de Bento Rodrigues confiavam nas informações da Samarco a respeito da segurança do processo, reiterada em várias entrevistas. Assim, a preocupação com risco nunca se concretizou em um movimento organizado com força para contrapor o discurso de segurança dos processos da Samarco e suas operações. A empresa continuou a expandir suas atividades no município, contribuindo para uma dependência cada vez maior de Mariana da atividade mineradora, reconhecida pelo representante da Samarco entrevistado. Ao se materializar o rompimento da barragem, o representante afirma que foi acionado o plano de emergência, tal como apresentado no processo de licenciamento ambiental, valorizado como um de seus procedimentos para controles de impactos ambientais e sociais, conforme relatado nos relatórios de sustentabilidade. No entanto, a empresa não cumpriu os requisitos do Plano Nacional de Segurança de Barragens (PNSB), que exige a instalação de um sistema de alarme 
sonoro e o fornecimento de equipes treinadas para aconselhar as comunidades em situações de emergência. A ação da empresa se limitou a comunicar o acidente à prefeitura e à defesa civil de Mariana, cujas equipes chegaram ao local algumas horas depois do rompimento da barragem. Diante da ausência de qualquer comunicação oficial, de equipes de socorro ou mesmo de instrução sobre como agir em situações de emergência, os moradores intuitivamente se abrigaram na parte alta do distrito. Para o representante da empresa, apesar da magnitude do impacto socioambiental, a confiança dos moradores na Samarco, construída ao longo dos anos, foi essencial, para minimizar conflitos e continuar o diálogo nesses momentos difíceis.

Apesar da revolta da comunidade, conseguimos continuar estabelecendo uma relação de confiança e construir soluções de resposta humanitária junto com as lideranças comunitárias. Três dias depois eu estava utilizando uniforme da própria empresa lá na região. Em outros casos isso seria impensável, o nível de conflito, de violência, seria muito grande. A comunidade percebeu que a empresa, apesar de tudo que ocorreu, estava ali querendo resolver, se comprometendo e buscando uma solução para tratar das questões (Representante da Samarco).

Nas falas dos moradores, no entanto, observa-se uma quebra muito grande do grau de confiança. A razão dessa frustração gira em torno da omissão por parte da mineradora dos problemas na barragem que já tinham sido constatados antes de seu rompimento - como demonstrou a investigação da força-tarefa montada pelo MPF para apurar as causas da tragédia, cujas conclusões foram em parte expostas anteriormente.

Lá dentro, da área deles, eles lutavam tanto por segurança, porque eles não se preocuparam com a gente aqui fora? Se existia um risco, a primeira coisa seria comunicar a comunidade de Bento. Não importa se [a barragem] ia estourar ou não, mas pelos menos eles tinham que nos avisar. Mas nem isso eles fizeram (Morador de Bento Rodrigues).

Outros elementos contraditórios também chamam atenção, como a questão da assistência prestada aos atingidos após a tragédia. O representante da empresa afirmou em entrevista que sua ação foi além das exigências legais, citando como boas práticas medidas que resultaram de intervenções do MP.

Implementamos um processo de resposta humanitária que foi muito além do que o plano de emergência estabeleceu, isso eu posso te falar porque eu desenhei o plano de resposta humanitária baseado nas melhores práticas que a gente encontrou no mundo pra desastres naturais e outras ações (Representante da Samarco).

As entrevistas com as autoridades em Mariana, entretanto, trazem elementos que descontroem essa linha argumentativa da empresa. Todas as ações da Promotoria de Direitos Humanos da Comarca de Mariana encontram-se registradas e apresentam indícios concretos de que pautaram as medidas tomadas pela empresa para assistência aos atingidos.

Tudo que a empresa fez até hoje, todas as reivindicações atendidas, ela o fez muito mais pela pressão do Ministério Público do que pelo reconhecimento propriamente ou do que era seu desejo fazer isso (Padre da Arquidiocese de Mariana).

Ainda segundo a promotoria de direitos humanos do MP de Minas Gerais, até certo momento a Samarco cumpriu grande parte do que foi exigido judicialmente, principalmente o assentamento das famílias em casas alugadas. Contudo, a empresa deixou de considerar muitas pessoas como atingidos: parou de entregar cartões de debito para as pessoas que dependiam de assistência financeira e de pagar as antecipações de indenizações.

A partir de determinado momento, quando o processo foi deslocado para a justiça federal, a Samarco aproveitou esse momento para negar muitos direitos para vários atingidos de uma forma absurda e inaceitável (Promotor).

Importante destacar também que o grau de dependência econômica do território em relação à Samarco acabou gerando um movimento no curto prazo para a retomada das operações da empresa.

Quinze dias depois da tragédia algumas pessoas de Mariana já estavam na rua, pedindo a volta da Samarco, foi muito triste. [...] Eles querem a empresa de volta mas ela quer voltar da mesma maneira, né? Aí volta do mesmo jeito, dali a pouco acontece outra vez (Morador Bento Rodrigues). 
Para os moradores de Bento Rodrigues, isso se constituiu um novo impacto em suas vidas, na medida em que a solidariedade no momento da tragédia acabou sendo substituída por uma visão negativa, em que os atingidos acabaram sendo responsabilizados pelos problemas econômicos enfrenados pelo município.

\section{DISCUSSÃO DOS RESULTADOS}

O caso Samarco expõe as limitações de modelos de RSC para situações envolvendo comunidades com baixo capital social. A crítica de Hilson (2012), pontuando que os modelos de RSC corporativos concebidos no âmbito das economias desenvolvidas, quando aplicados nos países em desenvolvimento, representam uma área cinza que necessita de mais pesquisa, parece encontrar um campo fértil no caso Samarco. O caso apresentado corrobora as críticas de Jenkins e Yakovleva (2006) sobre o descompasso entre as informações disponibilizadas em relatórios de sustentabilidade e as práticas efetivas das empresas. Os problemas operacionais da barragem, que davam sinais desde 2009, e seus riscos foram excluídos dos relatórios que enfatizavam a segurança de seus processos e a preparação da organização para tratar situações de emergência. Também ao considerar que as empresas de mineração têm um interesse cada vez maior em implementar sua RSC por meio de modelos como o da LSO (WILBURN e WILBURN, 2011), infere-se, a partir do estudo de caso realizado, que os modelos de Thomson e Boutilier (2011) e Moffat e Zhang (2014) centrados em relações de confiança podem em certos contextos ampliar a vulnerabilidade das comunidades no entorno de projetos minerários. Como afirmam Thomson e Boutilier (2011), quando a comunidade percebe a empresa como totalmente confiável, existe um sentimento de copropriedade, e a empresa se transforma em um membro da rede social local. A identificação psicológica, considerada pelos autores como grau mais elevado da LSO, pode ser encontrada nesse caso, agravando a situação de vulnerabilidade social e dependência econômica das comunidades locais.

Esta pesquisa mostra que a ênfase na manutenção da reputação corporativa, conforme propõem Nelsen e Scoble (2006), era prioritária nas ações da Samarco de forma a minimizar riscos de resistência ao projeto por parte das partes interessadas. Os investimentos na área de desenvolvimento socioinstitucional não promoveram o empoderamento das comunidades a fim de minimizar a relação de dependência econômica. Não foram identificados indícios a partir do trabalho de campo de que esses critérios - quando praticados pela Samarco - estavam de fato consolidados. Com efeito, não se encontrou elementos de que de fato havia processos sólidos de consulta e participação local resultantes de um diálogo tripartite entre comunidade, empresa e governos, conforme recomendam os estudiosos da LSO. A legitimidade da empresa junto à comunidade foi construída em função do desconhecimento de suas práticas efetivas, como no caso do risco da barragem. Apesar de ser um problema já identificado em 2009, isso não foi repassado para a comunidade, mesmo com o pedido feito por moradores de Bento Rodrigues para esclarecimento sobre a segurança da barragem. Para manter a percepção positiva da comunidade e minimizar as preocupações em relação à segurança de suas barragens, a empresa usou de artifícios como convidar representantes de Bento Rodrigues para visitar outra barragem de seu sistema, a de Santarém, como revelaram as entrevistas com os atingidos de Bento Rodrigues. Nesse sentido, as limitadas ações da empresa no campo da RSC, como investimentos pontuais na comunidade, contribuíam para a perda de capacidade crítica, configurando uma situação de resignação. Dessa forma, a percepção do risco da comunidade sobre a barragem não se concretizava em ações de embate contra a empresa, prevalecendo o discurso da Samarco da total segurança dos processos, repetindo os conteúdos disponibilizados nos relatórios.

No caso estudado, essa assimetria de poder, aliada à dependência econômica, culminou na pressão de parte da população pela volta de operação da Samarco, que conforme Milanez, Santos, Wanderley et al. (2015) somou-se aos esforços estatais e empresariais de tratar a tragédia como uma fatalidade e enquadrar a Samarco no rol das vítimas. 


\section{CONCLUSÕES}

A tragédia da Samarco, considerando seus enormes impactos ambientais, sociais e econômicos, implica em desafios na operacionalização de modelos de RSC elaborados nos contextos dos países desenvolvidos. Voltando à questão de pesquisa proposta nesse trabalho, infere-se que em um contexto marcado pelo baixo capital social das comunidades locais, elevado grau de dependência econômica e vulnerabilidade social, o modelo de RSC implantado na Samarco, a partir da disponibilização de informações em seus relatórios de sustentabilidade e critérios da LSO, demonstrou baixa efetividade. O diálogo, a transparência, a consulta, a gestão de riscos e os investimentos locais foram frequentemente mencionados nos documentos da empresa analisados. Como resultado, a Samarco era considerada um membro genuíno da rede social da comunidade. No entanto, o uso dessas estratégias priorizaram o monitoramento da percepção da imagem e reputação da empresa junto a seus diferentes stakeholders. Os investimentos na área de desenvolvimento socioinstitucional tampouco promoveram o empoderamento das comunidades para minimizar a relação de dependência econômica ou reduzir a vulnerabilidade social. Além disso, tais níveis de confiança e dependência econômica do município encobriram riscos ambientais, sociais e econômicos, aumentando a vulnerabilidade da população e da comunidade local.

O caso da Samarco também chama atenção para o fato de que os modelos de gestão convencionais não são eficientes para mitigação ou contingenciamento de grandes riscos que ultrapassam as fronteiras de tempo e espaço, uma vez que transcendem a mera avaliação ambiental da própria empresa ou do órgão licenciador. Diante disso, caberia à sociedade referendar a aprovação de uma atividade econômica que possa ocasionar danos da dimensão da tragédia em questão. No entanto, o caso apresentado mostra os diversos desafios para a efetividade de modelo de governança corporativa democrático, em que os diferentes atores da comunidade são ouvidos e empoderados nos processos de tomada de decisão que dizem respeito ao seu futuro. Nesse contexto, a questão de como capacitar a comunidade e garantir um ambiente institucional forte parecem ser o ponto-chave para se alcançar um processo completo e eficaz de RSC.

Outra constatação dá conta de que algumas boas práticas ocultaram ou desviaram a atenção para problemas de gestão graves, haja vista o não atendimento de exigências básicas do marco regulatório de barragens como a instalação de sistema de alerta e a disponibilização de equipes treinadas para assessorar as comunidades em casos de emergência. Além disso, observamos nos relatórios de sustentabilidade elementos apontando que os esforços relacionados à RSC e à manutenção da LSO estavam mais voltados à obtenção de uma reputação positiva em detrimento dos demais fatores levantados na literatura. Isso pode ter contribuído para uma situação de maior vulnerabilidade e até de cooptação das comunidades do entorno, tendo em vista que tampouco se encontraram indícios de uma comunicação transparente com relação aos riscos inerentes à atividade da empresa.

Embora este estudo apresente as limitações inerentes a uma pesquisa centrada em um único caso, acredita-se que os resultados reforçam a necessidade de aprofundar investigações relacionadas às fragilidades entre discurso e prática de iniciativas de RSC na realidade brasileira. Uma grande questão que se coloca é se a dimensão dessa tragédia representará um divisor de águas nos atuais modelos de gestão no setor de mineração que insistem em manter variáveis sociais e ambientais como questões marginais para a tomada de decisão. O setor de mineração, no entanto, tem pressionado pela flexibilização do processo de licenciamento, como ocorreu no estado de Minas Gerais, em que as mudanças no licenciamento ambiental atenderam a demandas do setor mineral, que vinha também pressionando o governo estadual a acelerar o processo de licenciamento. Tal posicionamento caminha na direção contrária dos potenciais aprendizados da tragédia de Mariana, tanto para as empresas como para o setor público, perpetuando um quadro de vulnerabilidade nos territórios em que se encontram numerosos empreendimentos minerários. 


\section{REFERÊNCIAS}

ANSELL, C.; GASH, A. Collaborative governance in theory and practice. Journal of Public Administration Research and Theory, n. 8, p. $543-$ 557, 2007.

BANCO MUNDIAL. Commodity markets. 2015. Disponível em: <http://www.worldbank.org/en/research/commodity-markets>. Acesso em: 5 jan. 2017.

BECK, U. Sociedade de risco: rumo a uma outra modernidade. 2. ed. São Paulo: Editora 34, 2011.

BOUTILIER, R. G.; BLACK, L.; THOMSON, I. From metaphor to management tool: how the social license to operate can stabilise the socio-political environment for business. In: INTERNATIONAL MINE MANAGEMENT, 2012, Melbourne. Proceedings... Melbourne: Internacional Mine Management, 2012. p. 227-237.

BRASIL. Ministério Público Federal. Procuradoria da República nos Estados de Minas Gerais e Espírito Santo - Força-Tarefa Rio Doce. Procedimento investigatório criminal (PIC) MPF n.o 1.22.000.000003/2016-04. Brasília: MPF, 2016. Disponível em: <http:// www.mpf.mp.br/mg/sala-de-imprensa/docs/denuncia-samarco>. Acesso em: 5 jan. 2017.

COISSI, J.; BRAGA, F. Lama de Mariana chega ao litoral do ES com protesto de moradores. Folha de S. Paulo, São Paulo, 21 nov. 2015. Disponível em: <http://www1.folha.uol.com.br/cotidiano/2015/11/1709414lama-de-mariana-chega-ao-mar-do-es-com-protesto-de-moradores. shtml>. Acesso em: 20 jun. 2016.

DAVIS, G. A.; TILTON, J. E. The resource curse. Natural Resources Forum, v. 29, n. 3, p. 233-242, 2005. Disponível em: <https:// onlinelibrary.wiley.com/doi/full/10.1111/j.1477-8947.2005.00133.x>. Acesso em: 31 mar. 2018.

DAVIES, M.; MARTIN, T. Mining market cycles and tailing dams incidents. In: INTERNATIONAL CONFERENCE ON TAILINGS AND MINE WASTE, 13, Banff. Proceedings... Banff: AB, 2009.

EISENHARDT, K. M. Building teories from case study research. Academy of Management Review, 1989.

O ESTADO DE S. PAULO. ANEFAC premia vinte empresas com troféu transparência. Agência Estado, São Paulo, 18 jul. 2013. Disponível em: <https://economia.estadao.com.br/noticias/negocios, anefacpremia-20-empresas-com-trofeu-transparencia,159532e>. Acesso em: 19 dez. 2017.

FERNANDES et al. Deep in the mud: ecological and social economic impacts of the dan breach in Mariana, Brazil. Brazilian Journal of Nature Conservation, v. 14, p. 35-45, 2016.

FRANKS, D. M. et al. Conflict translates environmental and social risk into business costs. National Academy of Sciences of the United States of America, v. 111, n. 21, p. 7576-81, 2014. Disponível em: <http://www.pnas.org/content/111/21/7576.short>. Acesso em: 31 mar. 2018.

FRANKS, D. M.; COHEN, T. Social license to operate. Constructive technology assessment within a mineral reserch and development institution. Technological Forecasting and Social Change, v. 79, n. 7, p. 1229-1240, 2012.
GUNNINGHAM, N.; KAGAN, R. A.; THORNTON, D. Social license and environmental protection: why businesses go beyond compliance. Law \& Social Inquiry, v. 29, n. 2, p. 307-341, 2004.

HILSON, G. Corporate social responsibility in the extrative industries: experiences from development countries. Resources Policy, v. 37, p. 131-137, 2012.

HOWARD-GRENVILLE, J.; NASH, J.; COGLIANESE, C. Constructing the license to operate: internal factors and their influence on corporate environmental decisions. Law and Policy, v. 30, n. 1, p. 73-107, 2008.

IBRAM - INSTITUTO BRASILEIRO DE MINERAÇÃO. Informações sobre a economia mineral brasileira 2015. Brasília: IBRAM, out. 205. Disponível em:<http://www.ibram.org.br/sites/1300/1382/00005957. pdf>. Acesso em: 31 mar. 2018.

JENKINS, H.; YAKOVLEVA, N. Corporate social responsibility in the mining industry: exploring trends in social enviromental disclosure. Journal of Cleaner Production, v. 14, p. 271-284, 2006.

JOYCE, S.; THOMSON, I. Earning a social licence to operate: social acceptability and resource development in Latin America social risk. Latin America sources of social risk. The Canadian Mining and Metallurgical Bulletin, v. 93, n. 1037, p. 1-9, 2000.

KNOKE, D. The political economies of associations. Research. Political Sociology, v. 1, n. 1, p. 211-242, 1985.

LOPES, J. A licença social para operar na atividade mineradora no Brasil: o caso Samarco e a gestão de riscos ampliados. 2017. 112p. Dissertação (Mestrado em Administração) - Centro Universitário da FEl, 2017.

MCMAHON, G.; REMY, F. Principales observaciones y recomendaciones: una síntesis de los estudios de caso. Grandes minas y la comunidad, p. 1-38, 2003.

MCWILLIAN, A.; SIEGEL, D. Corporate social responsibility: a theory of the firm P. Academy Management Journal, v. 26, p. 117-127, 2001.

MILANEZ, B. et al. Antes fosse mais leve a carga: avaliação dos aspectos econômicos, políticos e sociais do desastre da Samarco/ Vale/BHP em Mariana (MG). [S. I.: s. n.], 2015. Mimeo. Disponível em: <http://www.ufjf.br/poemas/files/2014/07/PoEMAS-2015Antes-fosse-mais-leve-a-carga-vers\%C3\%A3o-final.pdf>. Acesso em: 31 mar. 2018.

MOFFAT, K.; ZHANG, A. The paths to social licence to operate: an integrative model explaining community acceptance of mining. Resources Policy, v. 39, n. 1, p. 61-70, 2014.

NELSEN, J.; SCOBLE, M. Social license to operate mines: issues of situational analysis and process. Department of Mining Engineering, University of British Columbia, Vancouver, Feb., 2006.

PRNO, J. An analysis of factors leading to the establishment of a social licence to operate in the mining industry. Resources Policy, v. 38, n. 4, p. 577-590, 2013.

PRNO, J.; SLOCOMBE, D. S. Exploring the origins of "social license to operate" in the mining sector: Perspectives from governance and sustainability theories. Resources Policy, v. 37, n. 3, p. 346-357, 2012. 
ROCKSTRÖM, J. et al. A safe operating space for humanity. Nature, v. 461, n. 7263, p. 472-475, 2009.

SAMARCO. Relatório de Sustentabilidade 2005. [S.I.]: Samarco, 2005. Disponível em: <https://www.samarco.com/wp-content/ uploads/2016/08/2005-Relatorio-Anual-de-Sustentabilidade.pdf>. Acesso em: 01 maio 2017.

SAMARCO. Relatório de Sustentabilidade 2011. [S.I.]: Samarco, 2011. Disponível em: <https://www.samarco.com/wp-content/ uploads/2016/08/2011-Relatorio-Anual-de-Sustentabilidade.pdf>. Acesso em: 01 maio 2017.

SAMARCO. Relatório de Sustentabilidade 2012. [S.I.]: Samarco, 2012. Disponível em: <https://www.samarco.com/wp-content/ uploads/2016/08/2012-Relatorio-Anual-de-Sustentabilidade.pdf>. Acesso em: 01 maio 2017.

SAMARCO. Relatório de Sustentabilidade 2013. [S.I.]: Samarco, 2013. Disponível em: <https://www.samarco.com/wp-content/ uploads/2016/08/2013-Relatorio-Anual-de-Sustentabilidade.pdf>. Acesso em: 01 maio 2017.

SAMARCO. Relatório de Sustentabilidade 2014. [S.I.]: Samarco, 2014. Disponível em: <http://www.samarco.com/wp-content/ uploads/2016/08/2014-Relatorio-Anual-de-Sustentabilidade.pdf>. Acesso em: 01 maio 2017.

SANTIAGO, A. L. F. Licença social para operar relacionamento da empresa com a comunidade local: critérios de influência para a concessão da LSO. Um estudo de caso da mineração brasileira. 2016. 323f. Tese (Doutorado em Administração) - Centro Universitário FEI, São Paulo, 2016.

SANTIAGO, A. L. F.; DEMAJOROVIC, J. Social license to operate: a case study from a Brazilian mining industry. Latin American Journal of Management for Sustainable Development, v. 3, p. 19-34, 2016.

SCHNEIDER, A.; SCHERER, A. G. Corporate governance in a risk society. Journal of Business Ethics, n. 126, p. 309-323, 2015. Disponível em: <https://link.springer.com/article/10.1007/s10551-013-1943-4>. Acesso em: 31 mar. 2018.

SILVA, C. R.; GOBBI, B. C.; SIMÃO, A. O uso da análise de conteúdo como uma ferramenta para a pesquisa qualitativa: descrição e aplicação do método. Organizações Rurais \& Agroindustriais, v. 7, n. 1, 2011.

SOLOMON, F.; KATZ, E.; LOVEL, R. Social dimensions of mining: research, policy and practice challenges for the minerals industry in Australia. Resources Policy, v. 33, n. 3, p. 142-149, 2008.

THOMSON, I.; BOUTILIER, R. G. Social license to operate. In: DARLING, P. (Ed.). SME Mining engineering handbook. [S. I.: s. n.], 2011.

WILBURN, K. M.; WILBURN, R. Achieving social license to operate using stakeholder theory. Journal of International Business Ethics, v. 4, n. 2, 2011.

ZHANG, A. et al. Understanding the social licence to operate of mining at the national scale: a comparative study of Australia, China and Chile. Journal of Cleaner Production, v. 108, p. 1063-1072, 2015.

Juliana Campos Lopes

ORCID: https://orcid.org/0000-0003-4781-723X

Mestre em Administração pelo Programa de Pós-Graduação em Administação no Centro Universitário FEl, São Paulo - SP, Brasil.

E-mail: jcl.press@gmail.com

Jacques Demajorovic

ORCID: https://orcid.org/0000-0001-6131-8790

Doutor em Educação; Professor no Programa de Pós-Graduação em Administação do Centro Universitário FEI, São Paulo - SP, Brasil.

E-mail: Jacquesd@fei.edu.br 